$\begin{array}{lll} & \text { International Journal of Educational Studies in Mathematics } \\ \text { WWW.ijesim.com } & \text { ISSN: 2148-5984 }\end{array}$

\title{
The Effect of High Literacy Demands in Mathematics on International Students
}

\author{
Mark Prendergast*, Fiona Faulkner, Clare O’Hara \\ School of Education, Trinity College Dublin* \\ School of Hospitality Management and Tourism, Dublin Institute of Technology
}

\begin{abstract}
Project Maths is an ambitious reform of Irish post-primary education. It involves changes to what students learn in mathematics, how they learn it and how they will be assessed. There is a much greater emphasis placed on student understanding of mathematical concepts, with increased use of contexts and applications that will enable students to relate mathematics to their everyday experiences. The assessment reflects the different emphasis on problem solving and applications in the teaching and learning of mathematics and there is a much greater emphasis on reading and understanding the problems. Hence there is a greater emphasis on student's English language proficiency. This study aims to investigate the effect of Project Maths on international students studying in Ireland who do not speak English as their first language. As part of the study participants completed two sample examinations, one which comprised of mathematical word problems and the other which was technically the same examination but was mathematical procedure and skill based only. The results show a statistically significant difference between the mean scores of students in both examinations, with students performing better when the majority of language and context in questions was removed. This highlights the impact that literacy skills can play in the mathematics classroom.
\end{abstract}

Keywords: Project Maths, international students, students performing, mathematics classroom Mathematics, Language and Literacy, International Students.

(C) 2016 IJESIM. All rights reserved

Article History:

Received 03.09.2015 Received in revised form 01.02.2016 Accepted 21.04.2016 Available online 15.06.2016

\section{Introduction}

In Ireland formal education takes place in three stages, namely primary, second and thrid level. After completing eight years of primary education all students progress to second level education. This is typically of six years and during this time students complete two main State examinations namely the Junior Certificate (JC) and the Leaving Certificate (LC) examinations. These examinations can be taken at three levels with the upper level referred to as Higher, the next level referred to as Ordinary, and the lowest level that can be taken referred to as Foundation. Students can gain entry to Higher Education Institute's (HEI's) depending on how well they perform in the LC examinations. In this system the importance of mathematics is recognised by students, teachers and policy makers alike. Its inclusion as a compulsory subject in schools has widespread support (National Centre for Curriculum and Assessment (NCCA), 2005a) and students who achieve at least

\footnotetext{
${ }^{1}$ Corresponding author's address: School of Education, Trinity College Dublin, Dublin, Ireland.

Telephone:0035318964855

e-mail: mark.prendergast@tcd.ie

DOI: http://dx.doi.org/10.17278/ijesim.2016.02.003
} 
a D3 (greater than 40\%) in Higher level LC mathematics examinations are awarded bonus marks (Central Applications Office (CAO) -www.cao.ie).

However despite this importance, numerous concerns have been highlighted throughout the literature in recent years regarding mathematics educational strategy in Ireland. These concerns include class time, class and teacher allocation, difficult content, traditional assessment and an out of date curriculum (Prendergast and O'Donohue, 2014). Until recently, changes to this curriculum had not taken place since the 1960's when, even then, a major review of the Irish mathematics syllabuses at second level was undertaken highlighting "mathematical structures, abstraction and rigorous presentation" (Oldham, 1993). These syllabuses resulted in a highly didactic and procedural approach to mathematics teaching in Ireland (NCCA, 2005b). There was a formal, behaviourist style evident that consisted of whole class teaching and the repetition of skills and procedures demonstrated by the teacher (Morgan and Morris, 1999). This resulted in students learning the 'how' rather than the 'why' of mathematics (Prendergast and O'Donoghue, 2014). There was little or no emphasis on students' understanding the mathematics they were taught or indeed relating it to everyday life (Lyons et al., 2003). These concerns were compounded by the low numbers of students studying Higher level mathematics. For example in 2010, figures show that only 45 per cent of the Junior Cycle cohort took the JC Higher level mathematics' examination. More worryingly only 16 per cent opted for the Higher level LC examination. These figures are also very low in comparison to other subjects. For example, in the same year 68 per cent of students took Higher Level English in the JC examination, while 64 per cent took Higher level English in the LC examination. To further compound this problem, 10 per cent of students failed Ordinary level mathematics in their LC examination in 2010 (all statistics have been taken from the State Examinations Commission (SEC)- www.examinations.ie).

As a result of such poor performance in mathematics by second level students, concern is widespread in many Irish HEI's regarding the mathematical under - preparedness of their entrant's. This does not just affect mathematics courses, but also impacts on other courses such as science, technology, engineering, business and finance where mathematics provides an important basis for development. This has serious repercussions for the Irish economy, particularly in relation to the technology and industrial sectors (Expert Group on Future Skills Needs (EGFSN), 2008).

The Irish Government has been under increased pressure to take action as a result of such concerns. There was a stark realisation that the syllabuses and teaching methods were inadequate in providing students with the skills and knowledge which the twenty first century requires. Mathematics teaching today must emphasise the process of learning, applications of mathematics to the everyday world and problem solving (NCCA, 2005b). In order to achieve this aim and help solve the 'maths problem', the Irish Government have introduced a major new initiative in second level schools called Project Maths.

\section{Project Maths}

Project Maths overall aim is to teach mathematics in a way which leads to real understanding (Department of Education and Skills (DES), 2010a). It involves changes to what students learn in mathematics, how they learn it and how they will be assessed (www.projectmaths.ie). The initiative is designed to ensure an appropriate balance between understanding mathematical theory and concepts and developing practical applications skills. There is a much greater emphasis placed on student understanding of mathematical concepts, with increased use of contexts and applications that will enable students to relate mathematics to their everyday experiences. The focus is on students understanding the concepts involved, building from the concrete to the abstract and from the informal to the formal, and learning to apply their knowledge in familiar and unfamiliar contexts (DES, 2010a).

The Junior and Senior Cycle syllabuses are divided into five strands namely, Statistics and Probability; Geometry and Trigonometry; Number; Algebra; and Functions. After an initial pilot phase beginning with 24 schools in 2008, it was rolled out nationally in 2010. Changes are being phased in over a number of years covering all 5 strands of mathematics, with assessment in the examinations being adapted as each strand of mathematics comes on stream. The assessment reflects the different emphasis on problem solving and applications in the teaching and learning of mathematics and there is a much greater emphasis on reading and understanding the problems. It is an objective of Project Maths to increase the uptake of Higher level mathematics at LC to 30 per cent and to 60 per cent at JC (Cosgrove et al., 2012). While Strands 1 and 2 of the 
revised syllabi were first examined in 2012 at LC level in all schools, the phased implementation means that it will be 2017 before a first cohort of students who have experienced all 5 strands of Project Maths from 1st to 6th year will be examined. Thus it is very early to make any conclusions regarding the successes / failures of the initiative. However, an interim report commissioned by the NCCA and conducted by the National Foundation for Educational Research (NFER, UK) has been published and includes findings on students' attitudes and achievements. Overall this report found that there is emerging evidence of the positive impacts of Project Maths on students' experiences of, and attitudes towards, mathematics (Jeffers et al., 2013). Furthermore, students' are achieving more at individual strand level, and in some instances students appear to be successfully drawing together their knowledge across different mathematics topics (Jeffers et al., 2013). This suggests that students are beginning to acquire a deeper understanding of mathematics and how it can be applied (Jeffers et al., 2013).

However, despite such emerging evidence of the positive impacts on students' experiences of, and attitudes towards, mathematics, many challenges remain for Project Maths. The majority of these challenges centre on the manner of the implementation process and the availability of teaching and learning resources. However concern has also been expressed regarding the perceived literacy demands of the revised mathematics syllabus (Cosgrove et al., 2012; Jeffers et al., 2013). Such concerns highlight the importance of language and literacy in the teaching and learning of mathematics.

\section{Language and Mathematics}

Mathematics can be recognised as a language in its own right, a language which has its own vocabulary, grammar, symbols and punctuation (Ellerton and Clarkson, 1996). The teaching of mathematics, however, takes place within a spoken language, such as English (Zevenbergen, 2001). This spoken language is an essential element of the teaching and learning of the subject (Gorgorió \& Planas, 2001). It is the vehicle of communication within a mathematics classroom and provides the tool for teacher - student interactions (Smith and Ennis, 1961). Language permits mathematics learners to ask and answer questions, to convey their understanding and to discuss their answers with others. It also plays a significant role in the processing of mathematical text and the interpretation of questions (Hoosain, 1991). This is now particularly relevant in Ireland with the introduction of Project Maths where there is far greater emphasis solving word problems and applications. Students are required to translate every day problems into mathematics, solve them and then clarify their answers in the context of the original problem. Many teachers feel that students with low literacy levels and particularly international students for whom English is not a first language are struggling with comprehension of this material and the wordy nature of some of the questions (Cosgrove et al., 2012). 'the language used when phrasing a question poses a major problem for students whose literacy skills would be weak, they can therefore not answer a question they are mathematically capable of doing! This is a major issue!' (Cosgrove et al., 2012:72). Many students (including those studying at Higher Level) have also expressed difficulties interpreting word based problems and with providing written explanations for their solutions to mathematical problems. Students also appear to lack confidence when asked to draw conclusions from a considerable amount of written information (Jeffers et al., 2013).

\section{The Research Foci}

Approximately 1.7 million students, almost half of whom are from non - English speaking developing nations in Asia, cross borders every year to acquire a foreign education (Sawir, 2005). In Ireland, the percentage of international students has increased from 3 per cent in 2002 to 10 per cent in 2012 (Perkins et al., 2013). The Government aims to increase this further as it bids to promote the internationalisation of the Irish Higher Education sector and to significantly increase the proportion of fee paying international students as a means to diversify the income base for HEI's (DES, 2010b). This need to diversify the income base of institutions was further restated in the Hunt Report specifically referencing income generated from the recruitment of fee paying international students (Hunt, 2011). However, the increased arrival of international students has also coincided with the introduction of Project Maths in second level schools and its high emphasis on literacy and the English language. Of the 10 per cent of students in Ireland classified as international, about half speak 
languages other than Irish or English at home (Perkins et al., 2013). This research aims to investigate the effect (if any) which Project Maths has on international students and to view the initiative from their perspective.

\section{Methods}

The authors decided to use a mixed method approach by combining both qualitative (focus group) and quantitative (comparsion of exam scores and closed ended questions) methods of research. The use of multiple methods was decided upon in order to get an in-depth understanding of the research. The study evaluates international student's opinions of Project Maths and compares their scores in a traditional style mathematics examination with their scores in a Project Maths style examination. All of the data was collected by the authors in September 2013 in the participants first academic week of the programme.

\section{Participants}

The participants for this study comprised of 41 international students who were enrolled in an International Foundation Programme in an Irish HEI. Mathematics is one of six core year-long subjects that all students are required pass, along with two elective choices, in order to complete the programme. Upon successful completion of the programme, students are granted direct entry onto an undergraduate programme of their choice in the HEI. The aim of the programme is to equip them with the skills to meet the minimum entry requirements of such undergraduate programmes. All of the students who participated in the study originated from either Saudi Arabia or Oman and all spoke Arabic as their first language. Thus for many of these students, the main skills required involve improving their English language proficiency. This proficiency is measured using the International English Language Testing Score (IELTS). The IELTS is an internationally standardised 9 band scale. Each band corresponds to a level of English competence. All parts of the test (listening, reading, writing, speaking) and the Overall Band Score can be reported in whole and half bands, for example 6.5, 7.0, 7.5, 8.0.

In order to gain entry onto the Foundation Programme students must have an IELTS of at least level 5.0 or one whole band below the entry requirements of their undergraduate destination. Students with an IELTS of 5 are defined as modest English language users (www.ielts.org). They should have a partial command of the language, and although they are likely to make many mistakes, they should be able to cope with the overall meaning in most situations. Students with an IELTS of 6 are defined as competent English language users (www.ielts.org). They should have a generally effective command of the language despite some inaccuracies and misunderstandings. They should be able to use and understand fairly complex language, particularly in familiar situations. 58.5 per cent of the students who participated in this study had an overall IELTS of 5 and 24.4 per cent had an overall IELTS of 5.5. The remaining students had an overall IELTS of between 6 and 7.5.

\section{Quantitative Data}

In order to get a quantitative measure on the effect of Project Maths on international students the authors decided to compare the scores of students in Project Maths style examination (Exam A) with their scores in a traditional style mathematics examination (Exam B). Each examination comprised of ten questions from the Junior Cycle Number strand and each question was taken from Irish second level textbooks and previous State examination papers (SEC- www.examinations.ie). Students had 50 minutes to complete each examination. The questions in Exam A were based on the Project Maths method of assessment and thus reflected the emphasis on understanding, problem solving and applications. The questions in Exam B were technically the same questions from Exam A but were mathematical procedure and skill based only with the removal of any context or language. For example:

Exam A - Question 3

Usain Bolt, the fastest man on earth, has a stride length of $2 \frac{4}{5} \mathrm{~m}$ when he is at full stride. In a $100 \mathrm{~m}$ sprint, how many strides would Usain take to cover the final $30 \mathrm{~m}$ when he is at full stride?

Exam B - Question 3

Evaluate $30 \div 2 \frac{4}{5}$ 
Students completed Exam A first and then Exam B directly afterwards. Ten marks were awarded per question. Both examinations were corrected by a qualified Irish second level mathematics teacher who has six years experience in correcting State examinations. Each student received a mark out of 100 for each examination.

At the end of Exam B, there were also three closed ended questions which all participants were invited to answer. The questions enquired about which examination the participants preferred; which examination did they find more difficult; and whether their English language skills had negativity affected their ability to answer questions in either of the exams. These questions were further expanded upon more in the focus group.

\section{Qualitative Data}

In order to get feedback regarding international students' opinions of Project Maths, a focus group was conducted with eight students who volunteered from the examination participants. This focus group was conducted two days after the students completed the examinations. The quantitative findings from the examinations and closed ended questions were considered. Each student was coded to ensure confidentially (P1 - P8). Their responses were transcribed and analysed using NVivo software and arranged into themes by the authors and a mathematics education colleague.

\section{Results and Findings}

\section{Quantitative Data}

Descriptive analysis of the data shows that the students performed poorer in Exam A (M: 41.49; SD: 18.06) in comparison to Exam B (M: 63.59; SD: 16.84). A paired- samples $t$ - test found that there was a statistically significant difference in the performance of students in both examinations $(t(41)=-9.89, p=.000)$. As evidence in Table 1, further analysis of the data found that in Exam A, students with an IELTS of 5.5 (M: 52.60; SD: 15.36) performed much better than those with an IELTS of 5.0 (M: 34.08; SD: 16.41). An independent - samples $t-$ test also found that these differences were statistically significant $(t(41)=-3.05, p=.005)$.

Table 1: Comparing students mean and IELTS scores in Exam A

\begin{tabular}{|c|c|c|}
\hline Exam A & Students Mean Score & Standard Deviation \\
\hline IELTS 5 & 34.08 & 16.41 \\
\hline IELTS 5.5 & 52.60 & 15.36 \\
\hline
\end{tabular}

Such differences were not evident in Exam B (See Table 2) where students with an IELTS of 5.5 (M: 67.00; SD: 11.79) and an IELTS of 5.0 (M: 63.45; SD: 14.47) in Exam B performed similarly.

Table 2: Comparing students mean and IELTS scores in Exam B

\begin{tabular}{|c|c|c|}
\hline Exam B & Students Mean Score & Standard Deviation \\
\hline IELTS 5 & 63.45 & 14.47 \\
\hline IELTS 5.5 & 67.00 & 11.79 \\
\hline
\end{tabular}

The data collected from the three closed ended questions at the end of Exam B shows that 80.5 per cent of the participants preferred Exam B. 95.1 per cent found Exam A more difficult and 82.9 per cent felt that their English language skills had negatively affected their ability to answer questions in either of the exams.

\section{Quantitative Data}

Participants of the focus group gave a number of reasons why the majority of the participants preferred Exam B.

P4: 'Because it was straight forward'.

P6: 'There were no words which I can't understand'.

P7: 'I didn't have to translate the words; I could understand the method directly by the numbers'. 
However some also gave explanations why they preferred Exam A.

P2: 'It makes you think of the actual situation and it improves our English at the same time. Also, it's more fun than seeing a paper filled with numbers'.

P3: 'Because it helps us improve out language and our reading and it make us understand what we need'.

P8: 'It gave me the chance to use math in real life'.

There was a general conclusion amongst participants that Exam A was more difficult. Language and literacy levels were the foremost factors.

P1: 'In Exam A, most of the questions I didn't understand because I didn't know some words. It had hard expressions that an International student who's English is his second language wouldn't be able to understand'.

P8: 'The questions were written in a different language and that was the hard part. Understanding the question is half if the answer as we say in Arabic'

P6: 'Sometimes I think I had the solution, but because I did not understand the question, i solved it in the wrong way'.

P4: 'Some of the language was not familiar - the questions were like complicated short stories. Sometimes I could understand the words but found it hard to explain the answer'.

The allocated time was also consistently mentioned as a factor which made Exam A more difficult.

P3: 'In Exam A there is a lot of reading questions and it takes a long time to solve it especially for non-speaking English student'.

P8: 'Exam B was just numbers while Exam A was like reading English paragraphs which took more time'.

P2: 'we need to read the question many times to understand it and that may lose time'.

Overall their opinion of Project Maths was very positive.

P2: 'I think it is great because you can apply it in your daily use. I would like to see how it turns out because I think it has a bright future and it could change the way of teaching math all over the world'.

P3: 'I think it is enjoyable and good idea because we will use it in real life or work to solve problems and it helps us to improve our language'.

P8: 'I think it's a good practice to know how to use math, so the student will be able to solve real life problems using math. It also combines our language skills and our maths skills'.

However some did express reservations about the difficulty of Project Maths particularly for international students.

P8: 'The questions are more difficult to answer for international students when English is not first language'

P7: 'It might fail lots of students due to their lack of English'.

P4: 'It's difficult to understand the language as we are not native speakers. If I have good English I can answer it, if not, I will face some difficult things'.

Several participants offered suggestions about what could be done to help international students become more accustomed to the changes brought about by Project Maths.

P1: 'Keep the language of the questions basic. Don't use strong language that not everyone can understand'.

P2: 'I think if there was a class to teach math language and improve our language at the same time. Maybe more projects and discussion to give us more practice in English language in Maths'.

P7: 'We must improve our language - maybe classes where they just learned math vocab'.

\section{Discussion and Conclusion}

Similar to the findings of the 'Research into the impact of Project Maths on student achievement, learning and motivation' (Jeffers et al., 2013) and 'Teaching and Leaning in Project Maths: Insights from Teachers who Participated in PISA 2012' (Cosgrove et al., 2012) reports, this study highlights concern for international students for whom English is not a first language in how they manage the high literacy demands of Project Maths. The heavy emphasis on English language in the problem solving and application questions is difficult for international students. Statistically significant differences were found in the results of student 
scores in a traditional style mathematics examination with their scores in a Project Maths style examination. There was also statistically significant differences in the scores of students in the Project Maths style examination who had an IELTS of 5.5 compared to those who had an IELTS of 5.0. This shows that student's language levels were a main factor. To support this, 82.9 per cent of participants felt that their English language skills had negatively affected their ability to answer questions in either of the mathematics exams. These findings highlight the importance that language has on the teaching and learning process. A student can have excellent mathematical ability but this is futile unless they can communicate effectively with their teacher and their peers and can competently understand the language in which they are being taught and examined.

This study does not wish to convey negativity towards Project Maths. Indeed, the students of the focus group had very positive opinions of the initiative. However, it does wish to highlight that more needs to be done to cater for international students for whom English is not a first language, to ensure that they are not disadvantaged by Project Maths. The number of these students enrolling in Irish HEI's has soared in recent years. It is important that they are given every opportunity to succeed. The authors plans to extend this study further in the next academic year and put an educational intervention in place. International students will have part of their mathematics lecturers dedicated to improving their English mathematics vocabulary and their ability to solve real life and application based questions. A focus will be made to help students read questions, comprehend what they are being asked and also to help them explain their answers in English. If this proves to be a successful and worthwhile project, widespread rollout may be considered by Foundation Year Programmes in Irish HEI's. A high number of international students making a smooth transition to undergraduate courses is an important strategic aim of HEI's and indeed the Irish Government.

\section{References}

Central Applications Office (CAO) [online], available: www.cao.ie [accessed April 2014].

Cosgrove, J., Perkins, R., Shiel, G., Fish, R., \& McGuinness, L. (2012). Teaching and Leaning in Project Maths: Insights from Teachers who Participated in PISA 2012, Dublin: Educational research Centre.

Department of Education and Skills (2010a). Report of the Project Maths Implementation Support Group, Dublin: Department of Education and Skills.

Department of Education and Skills (2010b). Investing in Global Relationships - Irelands International Education Strategy 2010 - 15, Report of the High-Level Group on International Education to the Tánaiste and Minister for Education and Skills, Dublin: Department of Education and Skills.

Ellerton, N.F. and Clarkson, P.C. (1996). Language factors in mathematics teaching and learning, in A.J. Bishop et al (Eds.) International handbook of mathematics education (pp. 987-1033). The Netherlands: Kluwer Academic Publishers.

Expert Group on Future Skills Needs (2008). Statement on Raising National Mathematical Achievement, Dublin: EGFSN.

Gorgorió, N. and Planas, N. (2001). 'Teaching mathematics in multilingual classrooms', Educational Studies in Mathematics, 47(1), pp.7-33.

Hoosain, R. (1991). Psycholinguistic Implications for Linguistic Relativity: A Case Study of Chinese. Hillsdale, NJ: Lawrence Erlbaum.

Hunt, C. (2011). National Strategy for Higher Education to 2030 - Report of the Strategy Group, Dublin: Department of Education and Skills.

International English Language Testing Score (IELTS) [online], available: www.ielts.org [accessed April 2014]. Jeffes, J., Jones, E., Wilson, M., Lamont, E., Straw, S., Wheater, R. and Dawson, A. (2013). Research into the impact of Project Maths on student achievement, learning and motivation: final report. Slough: NFER.

Lyons, M., Lynch, K., Close, S., Sheerin, E. and Boland, P. (2003). Inside Classrooms- The Teaching and Learning of Mathematics in the Social Context, Dublin: Institute of Public Administration.

Morgan C. and Morris, G. (1999) Good Teaching and Learning: Pupils and Teachers Speak, London: Open University Press.

National Council for Curriculum and Assessment (NCCA) (2005a). Review of Mathematics in Post - Primary Education $_{\llcorner}$Department of Education and Science, Dublin: The Stationary Office. 
National Council for Curriculum and Assessment (NCCA) (2005b). International Trends in Post - Primary Mathematics Education [online], available: http://www.ncca.ie/uploadedfiles/mathsreview/intpaperoct.pdf [accessed March 2014].

Oldham, E. (1993). Senior cycle Mathematics Curricula in the Republic of Ireland: Courses for the 1990s Gospels, Epistles and Revelations? Irish Educational Studies, 12, 73-91

Perkins, R., Shiel, G., Merriman, B., Cosgrove, J. and Morgan, G. (2013). Learning for Life: The Achievements of 15 year olds on Mathematics, Reading Literacy and Science in PISA 2103, Dublin: Educational Research Centre.

Prendergast, M. and O'Donoghue, J. (2014). “Students enjoyed and talked about the classes in the corridors': pedagogical framework promoting interest in algebra', International Journal of Mathematical Education in Science and Technology (IJMEST) 45 (6): 795 - 812.

Sawir, E. (2005). Language Difficulties of International Students in Australia: The Effects of Prior Learning Experience. International Education Journal, 6(5), 567-580.

Smith, B. O and Ennis, R. H. (1961). Language and concepts. Chicago: Rand McNally \& company.

State Examinations Commission (SEC) [online], available: www.examinations.ie [accessed April 2014].

Zevenbergen, R. (2001). Changing contexts in tertiary mathematics: implications for diversity and equity, in D. Holton (Ed.) The Teaching and Learning of Mathematics at University Level, An ICMI Study. Dordrecht, The Netherlands: Kluwer Academic Publishers. 